\title{
Cross-reactivity profiles of hybrid capture II, cobas, and APTIMA human papillomavirus assays: split-sample study
}

Sarah Preisler ${ }^{1,2^{*}}$, Matejka Rebolj ${ }^{3}$, Ditte Møller Ejegod ${ }^{2}$, Elsebeth Lynge ${ }^{3}$, Carsten Rygaard $^{2}$ and Jesper Bonde ${ }^{1,2}$

\begin{abstract}
Background: High-risk Human Papillomavirus (HPV) testing is replacing cytology in cervical cancer screening as it is more sensitive for preinvasive cervical lesions. However, the bottleneck of HPV testing is the many false positive test results (positive tests without cervical lesions). Here, we evaluated to what extent these can be explained by crossreactivity, i.e. positive test results without evidence of high-risk HPV genotypes. The patterns of cross-reactivity have been thoroughly studied for hybrid capture II (HC2) but not yet for newer HPV assays although the manufacturers claimed no or limited frequency of cross-reactivity. In this independent study we evaluated the frequency of crossreactivity for HC2, cobas, and APTIMA assays.

Methods: Consecutive routine cervical screening samples from 5022 Danish women, including 2859 from women attending primary screening, were tested with the three evaluated DNA and mRNA HPV assays. Genotyping was undertaken using CLART HPV2 assay, individually detecting 35 genotypes. The presence or absence of cervical lesions was determined with histological examinations; women with abnormal cytology were managed as per routine recommendations; those with normal cytology and positive high-risk HPV test results were invited for repeated testing in 18 months.
\end{abstract}

Results: Cross-reactivity to low-risk genotypes was detected in 109 (2.2\%) out of 5022 samples on HC2, 62 (1.2\%) on cobas, and 35 (0.7\%) on APTIMA with only 10 of the samples cross-reacting on all 3 assays. None of the 35 genotypes was detected in 49 (1.0\%), $162(3.2 \%)$, and 56 (1.1\%) samples, respectively. In primary screening at age 30 to 65 years $(n=2859)$, samples of $72(25 \%)$ out of 289 with high-risk infections on HC2 and < CIN2 histology were due to cross-reactivity. On cobas, this was 106 (26\%) out of 415, and on APTIMA 48 (21\%) out of 224.

Conclusions: Despite manufacturer claims, all three assays showed cross-reactivity. In primary cervical screening at age $\geq 30$ years, cross-reactivity accounted for about one quarter of false positive test results regardless of the assay. Cross-reactivity should be addressed in EU tenders, as this primarily technical shortcoming imposes additional costs on the screening programmes.

Keywords: Human papillomavirus, Cervical cancer, HPV assays, Cross-reactivity, Clinical performance, Mass screening

\footnotetext{
* Correspondence: sarah.preisler@regionh.dk

${ }^{1}$ Clinical Research Centre and Department of Pathology, Copenhagen

University Hospital Hvidovre, Kettegård Allé 30, 2650 Hvidovre, Denmark

${ }^{2}$ Department of Pathology, Copenhagen University Hospital Hvidovre,

Kettegård Allé 30, 2650 Hvidovre, Denmark

Full list of author information is available at the end of the article
} 


\section{Background}

High-risk human papillomavirus (HPV) is a necessary cause of cervical cancer. HPV testing is currently widely used for triage of women with cytological abnormalities i.e. atypical squamous cells of undetermined significance (ASCUS) and as a test of cure $[1,2]$. In European countries including Norway, the Netherlands, Italy, Spain, Denmark, and Sweden primary HPV-based cervical screening is being piloted or a full-scale roll out is planned. In the USA, primary screening is at present undertaken as co-testing using cytology and HPV testing, but new recommendations advocate stand-alone HPV testing [3]. The role of HPV testing in screening is supported by the objectivity of test result read-outs and an improved protection of women from developing cervical cancer compared to cytology [4]. However, it is less specific for disease because most HPV infections clear spontaneously without leading to abnormalities. This means that false-positive test results, and the associated unnecessary diagnostic procedures, are common.

More than $100 \mathrm{HPV}$ genotypes have been identified, of which 13 are high-risk $(16,18,31,33,35,39,45,51,52$, 56, 58, 59, and 68) [5]. Cross-reactivity of HPV assays to untargeted, low-risk (non-oncogenic), genotypes has been considered as a possible cause of false-positive HPV test results.

Cross-reactivity has only been systematically and independently evaluated for the most widely used assay, hybrid capture II (HC2), where it was most frequently due to low-risk genotypes 53, 66, and 70 [6-11]. The intensity of the positive signal in cross-reacting samples tended to be relatively weak $[7,8,10]$, and the likelihood of cross-reactivity increased in multiple low-risk infections [6]. Most importantly, cross-reacting samples were rarely associated with high-grade cervical intraepithelial neoplasia (CIN) $[6-8,10]$-clearly showing that crossreactivity contributes to false-positive test results.

For more recently introduced commercially available assays, cross-reactivity profiles have not been independently established. Based on the data from the Danish Horizon study, we evaluated the frequency of crossreactivity for $\mathrm{HC} 2$, cobas, and APTIMA in a large splitsample study.

\section{Methods}

\section{Setting}

In Denmark, women aged 23-65 years are invited for cytology-based cervical screening every three (age $<50$ years) or every 5 years ( $\geq 50$ years). The design of the Horizon study was described in detail previously [12-17]. In short, consecutive SurePath samples from 5034 women evaluated at the Department of Pathology, Copenhagen University Hospital, Hvidovre, were tested with HC2, cobas, and APTIMA, and genotyped by
CLART HPV2 Assay (Genomica, Madrid, Spain). All SurePath cytology was read under routine conditions following the Bethesda 2011 system using FocalPoint Slide Profiler and Imaging systems. Women with abnormal cytology ( $\geq$ ASCUS) were managed according to routine screening recommendations. Women with normal cytology and a positive test result on at least one of the four HPV assays were additionally invited in 1.5 year for repeated cytology and HPV testing. For each woman, the worst histological diagnosis until December 2013, i.e. in approximately 2.5 years after the baseline testing, was retrieved from the nationwide Danish Pathology Data Bank (Patobank) [18].

\section{HPV testing}

Cytology post-quot material was used for $\mathrm{HC} 2$ testing. The remaining HPV testing was undertaken on the original residual material diluted with SurePath (approximately 1:1). All testing was undertaken in strict concordance with the protocols issued and agreed upon with the manufacturers. The instrumentation was supplied and maintained by the manufacturers. Cut-offs for positive test results were set by the manufacturers: RLU/ $\mathrm{CO} \geq 1.0$ for $\mathrm{HC} 2$; CT $\leq 40.5, \leq 40.0$, and $\leq 40.0$ for cobas's channels 16,18 , and other high-risk, respectively; and S/ $\mathrm{CO} \geq 0.5$ for APTIMA.

CLART was used as the full genotyping reference assay. This $L 1$ DNA PCR assay reports 35 genotypes individually, including the 13 high-risk and 22 low-risk (6, $11,26,40,42,43,44,53,54,61,62,66,70,71,72,73$, $81,82,83,84,85$, and 89). It uses modified PGMY09/11 primers with amplification products hybridized onto a low density microarray. The amplified viral sequences are approximately 465 base pairs (bp) long, dependent on the genotype. Visualization was performed and thereafter automatically read on the CLART array reader (Genomica). A spiked rhCFTR plasmid is used as process control, while a DNA control of the human CFTR gene validates material sufficiency.

HC2 detects, collectively, the 13 high-risk HPV genotypes. The assay is based on hybridisation of viral DNA to a high-risk RNA probe cocktail. No retest range was used. Cobas is a real-time PCR analysis detecting the 13 high-risk genotypes plus genotype 66 . The assay separately identifies genotypes 16 and 18, while the remaining 12 are detected collectively ("other high-risk"). The amplicons are approximately $165 \mathrm{bp}$ long. APTIMA detects E6/E7 mRNA expression of the 13 high-risk genotypes plus genotype 66 collectively using transcription-mediated amplification (TMA).

\section{Statistical analysis}

Cross-reacting samples were defined as those with positive test results without evidence of high-risk HPV 
genotypes by CLART. A sample cross-reacting to lowrisk genotypes was defined as one with a positive test result in which CLART detected only genotypes not targeted by the evaluated assay. This means that for $\mathrm{HC} 2$, cross-reactivity to low-risk genotypes was measured for 22 genotypes including genotype 66. For cobas and APTIMA assays, evaluation was undertaken for 21 genotypes, as they are both designed to detect genotype 66 . Samples with a positive test result cross-reacting to unconfirmed genotypes, defined as non-CLART genotypes, were included in the analysis but evaluated separately $[7,8,11]$. From 5034 samples, 12 were invalid on CLART, reducing the number of eligible samples to 5022 .

Assay-specific absolute cross-reactivity was defined as the proportion of cross-reacting samples among all studied samples, and assay-specific relative cross-reactivity as the proportion of cross-reacting samples among all samples with a positive test result. Genotypes most frequently involved in cross-reactivity were determined based on the distributions in single infections.

We used signal strength as a relative indicator of the amount of the viral target input material, and described its distribution with the median and interquartile range. If cobas returned a positive test result on more than one channel, the channel with the strongest signal was included in the analysis.

False-positive samples were defined as samples with a positive test result that were not followed by a diagnosis of $\geq$ CIN2. The origin of the samples was defined as primary screening or referral population using information on the women's testing histories registered in the Patobank since January 2000. Referral population samples $(n=887)$ were defined as either primary screening samples showing abnormal cytology at any age, or as samples with a recent abnormality, regardless of age and cytology. A recent abnormality was defined as a preceding cervical cancer diagnosis, a histological CIN diagnosis in $\leq 3$ years, cytological low-grade squamous intraepithelial lesions (LSIL) or worse, inadequate cytology, or a positive HPV test result in $\leq 12$ months, and less abnormal cervical cytological or histological diagnoses in $\leq 15$ months. Samples without a recent abnormality were predominantly screening samples. Since HPV screening has been discouraged for younger women [19], the primary screening population was restricted to $30-65$ years $(n=2859)$. Cross-reactivity was compared between different groups by calculating relative proportions and their $95 \%$ confidence intervals by assuming lognormal distribution.

\section{Results}

Cross-reactivity by assay

Among 5022 unselected samples (range: 16-89 years, mean $=37.3, \mathrm{SD}=12.3,4748$ (95 \%) 23-65 years), 1262
(25\%) had at least one of the 13 high-risk genotypes detected by CLART, and 1333 (27\%) when genotype 66 was included. Furthermore, 1024 (20 \%) were positive on HC2, 1345 (27 \%) on cobas, and 838 (17\%) on APTIMA (Table 1). Of these, CLART detected only lowrisk genotypes in 109 samples for HC2, 62 for cobas, and 35 for APTIMA. Acknowledging that crossreactivity was assessed based on one more genotype for HC2 than for cobas and APTIMA (genotype 66), absolute cross-reactivity to low-risk genotypes was $2.2,1.2$, and $0.7 \%$, respectively, and relative cross-reactivity was 10.6, 4.6, and 4.2\%, respectively. Absolute crossreactivity to low-risk genotypes was significantly higher for $\mathrm{HC} 2$ than for the other assays, and that of cobas was significantly higher compared to APTIMA. Relative cross-reactivity to low-risk genotypes was significantly higher for $\mathrm{HC} 2$, and statistically similar between cobas and APTIMA.

Absolute cross-reactivity to unconfirmed genotypes was $1.0 \%$ on $\mathrm{HC} 2,3.2 \%$ on cobas, and $1.1 \%$ on APTIMA, and relative cross-reactivity was $4.8,12.0$, and $6.7 \%$, respectively. Absolute cross-reactivity to unconfirmed genotypes was significantly higher for cobas than for the other two assays.

Cross-reactivity to low-risk genotypes was more frequent in younger women and in abnormal cytology (Table 2). Cross-reactivity to unconfirmed genotypes did not show a trend by age, but was, for cobas and APTIMA, somewhat more frequent in normal cytology.

Relative cross-reactivity to low-risk genotypes on all three assays was not significantly different in the referral compared to the primary screening population. Absolute cross-reactivity to low-risk genotypes, however, was significantly lower on $\mathrm{HC} 2$ and cobas in the screening than in the referral population. This is probably a reflection of a lower HPV prevalence in primary screening. The patterns were different for cross-reactivity to unconfirmed genotypes, with relative cross-reactivity being more frequent in the screening than in the referral population (Table 1).

\section{Cross-reactivity concordance?}

Only 10 (6\%) of 157 samples cross-reacting to low-risk genotypes did so on all three assays (Fig. 1a). Of the 109 HC2 cross-reacting samples, 73 (67 \%) were negative on cobas and APTIMA, and 24 of these involved genotype 66. Cobas had 36 (58 \%) unique cross-reacting samples out of all 62, whereas APTIMA had 9 (26\%) out of 35. In total, $75 \%$ of the 157 samples cross-reacting to lowrisk genotypes were positive on only one assay. Among the 223 samples cross-reacting to unconfirmed genotypes, concordance was similarly low, with $12(5 \%)$ being positive on all three assays; $86 \%$ of 223 samples were positive on only one (Fig. 1b). 
Table 1 Samples cross-reacting to low-risk and unconfirmed genotypes

\begin{tabular}{|c|c|c|c|c|}
\hline & $\begin{array}{l}\text { Total (any of the } \\
\text { three assays) }\end{array}$ & $\mathrm{HC2}$ & cobas & APTIMA \\
\hline \multicolumn{5}{|l|}{ Overall } \\
\hline $\begin{array}{l}\text { Positive test results, Total population } \\
(N=5022)\end{array}$ & 1505 & 1024 (20.4 \%) & $1345(26.8 \%)^{a}$ & $838(16.7 \%)^{a}$ \\
\hline $\begin{array}{l}\text { Positive test results, Primary screening } \\
\text { population age } 30-65 \text { years }(N=2859)\end{array}$ & 553 & $335(11.7 \%)$ & $464(16.2 \%)$ & $270(9.4 \%)$ \\
\hline $\begin{array}{l}\text { Positive test results, Referral population } \\
(N=887)\end{array}$ & 499 & $401(45.2 \%)$ & $453(51.1 \%)$ & $332(37.4 \%)$ \\
\hline \multicolumn{5}{|l|}{$\begin{array}{l}\text { Cross-reactivity to } \\
\text { low-risk genotypes }\end{array}$} \\
\hline \multicolumn{5}{|l|}{ Total population $(N=5022)$} \\
\hline Cross-reacting samples & 157 & 109 & 62 & 35 \\
\hline Absolute cross-reactivity & - & 109/5022 (2.2\%) & $62 / 5022(1.2 \%)$ & $35 / 5022(0.7 \%)$ \\
\hline Absolute cross-reactivity (vs. HC2) & - & 1 (reference) & 0.6 (0.4 to 0.8$)$ & $0.3(0.2$ to 0.5$)$ \\
\hline Relative cross-reactivity & - & 109/1024 (10.6\%) & $62 / 1345(4.6 \%)$ & $35 / 838(4.2 \%)$ \\
\hline Relative cross-reactivity (vs. HC2) & - & 1 (reference) & $0.4(0.3$ to 0.6$)$ & $0.4(0.3$ to 0.6$)$ \\
\hline \multicolumn{5}{|l|}{$\begin{array}{l}\text { Primary screening population, age } \\
30-65 \text { years }(N=2859)\end{array}$} \\
\hline Cross-reacting samples & 61 & 43 & 20 & 13 \\
\hline Absolute cross-reactivity & - & $43 / 2859(1.5 \%)$ & $20 / 2859(0.7 \%)$ & $13 / 2859(0.5 \%)$ \\
\hline Absolute cross-reactivity (vs. HC2) & - & 1 (reference) & 0.5 (0.3 to 0.8$)$ & $0.3(0.2$ to 0.6$)$ \\
\hline Relative cross-reactivity & - & 43/335 (12.8\%) & 20/464 (4.3\%) & $13 / 270(4.8 \%)$ \\
\hline Relative cross-reactivity (vs. HC2) & - & 1 (reference) & 0.3 (0.2 to 0.6$)$ & $0.4(0.2$ to 0.7$)$ \\
\hline \multicolumn{5}{|l|}{ Referral population $(N=887)$} \\
\hline Cross-reacting samples & 58 & 47 & 16 & 8 \\
\hline Absolute cross-reactivity & - & 47/887 (5.3 \%) & 16/887 (1.8\%) & 8/887 (0.9 \%) \\
\hline Absolute cross-reactivity (vs. HC2) & - & 1 (reference) & $0.3(0.2$ to 0.6$)$ & $0.2(0.1$ to 0.4$)$ \\
\hline Relative cross-reactivity & - & 47/401 (11.7\%) & 16/453 (3.5 \%) & 8/332 (2.4 \%) \\
\hline Relative cross-reactivity (vs. HC2) & - & 1 (reference) & $0.3(0.2$ to 0.5$)$ & 0.21 (0.1 to 0.4$)$ \\
\hline \multicolumn{5}{|l|}{ Primary screening vs. referral population } \\
\hline $\begin{array}{l}\text { Absolute cross-reactivity (95\% } \\
\text { confidence interval) }\end{array}$ & - & $0.3(0.2$ to 0.4$)$ & $0.4(0.2$ to 0.7$)$ & $0.5(0.2$ to 1.2$)$ \\
\hline $\begin{array}{l}\text { Relative cross-reactivity ( } 95 \% \\
\text { confidence interval) }\end{array}$ & - & $1.1(0.7$ to 1.6$)$ & $1.2(0.6$ to 2.3$)$ & 2.0 (0.8 to 4.8$)$ \\
\hline \multicolumn{5}{|l|}{$\begin{array}{l}\text { Cross-reactivity to } \\
\text { unconfirmed genotypes }\end{array}$} \\
\hline \multicolumn{5}{|l|}{ Total population $(N=5022)$} \\
\hline Cross-reacting samples & 223 & 49 & 162 & 56 \\
\hline Absolute cross-reactivity & - & 49/5022 (1.0\%) & 162/5022 (3.2 \%) & $56 / 5022(1.1 \%)$ \\
\hline Absolute cross-reactivity (vs. HC2) & - & 1 (reference) & 3.3 (2.4 to 4.5$)$ & 1.1 (0.8 to 1.7$)$ \\
\hline Relative cross-reactivity & - & 49/1024 (4.8 \%) & $162 / 1345(12.0 \%)$ & $56 / 838(6.7 \%)$ \\
\hline Relative cross-reactivity (vs. HC2) & - & 1 (reference) & 2.5 (1.8 to 3.4$)$ & 1.4 (1.0 to 2.0$)$ \\
\hline \multicolumn{5}{|l|}{$\begin{array}{l}\text { Primary screening population, age } \\
30-65 \text { years }(N=2859)\end{array}$} \\
\hline Total positive test results & 553 & $335(11.7 \%)$ & $464(16.2 \%)$ & $270(9.4 \%)$ \\
\hline Cross-reacting samples & 126 & 30 & 87 & 36 \\
\hline Absolute cross-reactivity & - & $30 / 2859(1.0 \%)$ & 87/2859 (3.0 \%) & $36 / 2859(1.3 \%)$ \\
\hline Absolute cross-reactivity (vs. HC2) & - & 1 (reference) & 2.9 (1.9 to 4.4$)$ & $1.2(0.7$ to 1.9$)$ \\
\hline
\end{tabular}


Table 1 Samples cross-reacting to low-risk and unconfirmed genotypes (Continued)

\begin{tabular}{|c|c|c|c|c|}
\hline Relative cross-reactivity & - & $30 / 335(9.0 \%)$ & $87 / 464(18.8 \%)$ & $36 / 270(13.3 \%)$ \\
\hline Relative cross-reactivity (vs. HC2) & - & 1 (reference) & $2.1(1.4$ to 3.1$)$ & 1.5 (0.9 to 2.4$)$ \\
\hline \multicolumn{5}{|l|}{ Referral population $(N=887)$} \\
\hline Total positive test results & 499 & $401(45.2 \%)$ & $453(51.1 \%)$ & $332(37.4 \%)$ \\
\hline Cross-reacting samples & 37 & 9 & 27 & 8 \\
\hline Absolute cross-reactivity & - & 9/887 (1.0 \%) & 27/887 (3.0 \%) & 8/887 (0.9 \%) \\
\hline Absolute cross-reactivity (vs. HC2) & - & 1 (reference) & $3.0(1.4$ to 6.3$)$ & 0.9 (0.3 to 2.3$)$ \\
\hline Relative cross-reactivity & - & $9 / 401(2.2 \%)$ & $27 / 453(6.0 \%)$ & 8/332 (2.4\%) \\
\hline Relative cross-reactivity (vs. HC2) & - & 1 (reference) & $2.3(1.3$ to 5.6$)$ & 1.1 (0.4 to 2.8) \\
\hline \multicolumn{5}{|l|}{ Primary screening vs. referral population } \\
\hline $\begin{array}{l}\text { Absolute cross-reactivity (95 \% } \\
\text { confidence interval) }\end{array}$ & - & $1.0(0.5$ to 2.2$)$ & $1.0(0.7$ to 1.5$)$ & $1.4(0.7$ to 3.0$)$ \\
\hline $\begin{array}{l}\text { Relative cross-reactivity (95 \% } \\
\text { confidence interval) }\end{array}$ & - & $4.0(1.9$ to 8.3$)$ & 3.1 (2.1 to 4.7$)$ & 5.5 (2.6 to 11.7$)$ \\
\hline
\end{tabular}

One of the six samples cross-reacting to low-risk genotypes with histologically confirmed high-grade lesions was a cervical cancer, detected by all three assays (Table 3). Of the five CIN2/3, one was detected by $\mathrm{HC} 2$ and APTIMA (CIN 2), two by $\mathrm{HC} 2$ and cobas (one CIN2 and one CIN3), and two (both CIN3) only by HC2. One CIN3 was detected by all three assays but CLART detected no genotypes.

\section{Multiple infections}

As also described previously [7], the likelihood of an assay returning a positive test result increased with the number of genotypes present in the sample (Table 4). This was observed for all three assays.

\section{Signal strength}

For all three assays, the median signal strength was weaker for samples cross-reacting to low-risk genotypes than for samples with high-risk genotypes confirmed by CLART (Fig. 2). In samples cross-reacting to unconfirmed genotypes, the median signal strength levels tended to be lower than in samples cross-reacting to low-risk genotypes.

\section{Most frequently cross-reacting low-risk genotypes}

For $\mathrm{HC} 2$, the most frequent cross-reacting infections were 66 (20), 70 (19), 53 (18), and 82 (14\%; Table 5). Several other genotypes also showed cross-reactivity, but in $<10 \%$ of all infections. On cobas, the frequent crossreacting genotypes were 70 (19) and 61 (15\%). On APTIMA, although based on very low numbers, genotypes 70 (36), 62 (16), 61 (12), 82 (12), and 83 (12\%) dominated. Genotype distributions were similar in multiple infections, with genotypes 44,71 , and 72 detected only in cross-reacting samples with multiple infections. Genotypes $40,43,85$, and 89 , all very infrequent in this population [12], did not appear to be involved in crossreactivity.

On cobas, $5 \%$ of samples with a positive test result on channel 16 alone contained only low-risk genotypes (Table 6). For channels 18 and other high-risk, the proportions were similar at 7 and $6 \%$, respectively. Of all samples cross-reacting to low-risk genotypes, $77 \%$ (48/ 62) were on other high-risk channel alone. Similar proportions, in the range of 14-18\% for the three channels, were also found for cross-reactivity to unconfirmed genotypes.

\section{Effect of cross-reactivity on the proportions of women} with false-positive test results

Cross-reactivity explained a measurable part of all falsepositive test results (Table 7 ). In primary screening at 30-65 years, about one in four false-positive HPV test result was due to cross-reactivity. Had there been no cross-reactivity, 7.6 instead of $10.1 \%$ of women would have had a false-positive test result on $\mathrm{HC} 2$. On cobas, this would have been $10.8 \%$ instead of $14.5 \%$, and $6.2 \%$ instead of $7.8 \%$ on APTIMA.

\section{Discussion}

\section{General findings}

In Danish routine SurePath samples, the patterns of HPV cross-reactivity for $\mathrm{HC} 2$ resembled those that were described previously. Cobas has been advertised as a HPV assay that does not cross-react to low-risk genotypes [20], whereas APTIMA's package insert cites cross-reactivity to genotypes $26,67,70$, and 82 , which are phylogenetically related to high-risk genotypes [21]. 
Table 2 Characteristics of cross-reacting samples in 5022 women

\begin{tabular}{|c|c|c|c|c|}
\hline & Total (any of the three assays) & $\mathrm{HC2}$ & cobas & APTIMA \\
\hline \multicolumn{5}{|c|}{ Cross-reactivity to low-risk genotypes } \\
\hline \multicolumn{5}{|l|}{ Age } \\
\hline$<30$ years $(n=1683)$ & 75 & $51(3.0 \%)$ & $34(2.0 \%)$ & $15(0.9 \%)$ \\
\hline$\geq 30$ years $(n=3339)$ & 82 & $58(1.7 \%)$ & $28(0.8 \%)$ & $20(0.6 \%)$ \\
\hline \multicolumn{5}{|l|}{ Concurrent cytology } \\
\hline Normal $(n=4630)$ & 116 & $71(1.5 \%)$ & $56(1.2 \%)$ & $29(0.6 \%)$ \\
\hline Abnormal $(n=367)$ & 40 & $37(10.1 \%)$ & $6(1.6 \%)$ & $6(1.6 \%)$ \\
\hline Inadequate $(n=25)$ & 1 & $1(4.0 \%)$ & $0(0.0 \%)$ & $0(0.0 \%)$ \\
\hline \multicolumn{5}{|l|}{ Histology outcome } \\
\hline CIN2 $(n=60)$ & 2 & $2(3.3 \%)$ & $0(0.0 \%)$ & $1(1.7 \%)$ \\
\hline CIN3 or worse $(n=118)^{a}$ & 4 & $4(3.4 \%)$ & $2(1.7 \%)$ & $1(0.8 \%)$ \\
\hline \multicolumn{5}{|c|}{ Cross-reactivity to unconfirmed genotypes } \\
\hline \multicolumn{5}{|l|}{ Age } \\
\hline$<30$ years $(n=1683)$ & 73 & $15(0.9 \%)$ & $56(3.3 \%)$ & $15(0.9 \%)$ \\
\hline$\geq 30$ years $(n=3339)$ & 150 & $34(1.0 \%)$ & $106(3.2 \%)$ & $41(1.2 \%)$ \\
\hline \multicolumn{5}{|l|}{ Concurrent cytology } \\
\hline Normal $(n=4630)$ & 214 & $44(1.0 \%)$ & 157 (3.4\%) & $54(1.2 \%)$ \\
\hline Abnormal $(n=367)$ & 7 & $4(1.1 \%)$ & $3(0.8 \%)$ & $2(0.5 \%)$ \\
\hline Inadequate $(n=25)$ & 2 & $1(4.0 \%)$ & $2(8.0 \%)$ & $0(0.0 \%)$ \\
\hline \multicolumn{5}{|l|}{ Histology outcome } \\
\hline CIN2 $(n=60)$ & 0 & $0(0.0 \%)$ & $0(0.0 \%)$ & $0(0.0 \%)$ \\
\hline CIN3 or worse $(n=118)^{a}$ & 1 & $1(0.8 \%)$ & $1(0.8 \%)$ & $1(0.8 \%)$ \\
\hline
\end{tabular}

${ }^{a}$ Of which three cases of cervical cancer

In our study, however, both appeared to cross-react to low-risk genotypes from various phylogenetic clades including those that do not include high-risk genotypes.

The frequency of cross-reactivity to low-risk genotypes was most frequently observed on HC2. The number of samples in which none of the 35 CLART genotypes was detected was surprisingly high especially for cobas. When both types of cross-reactivity were combined, about a quarter of samples with a false-positive test result in primary screening at age 30-65 years appeared to be cross-reacting on any of the three assays.
For all three assays, the most frequently involved cross-reacting genotypes were $53,61,62,70,82$, and for $\mathrm{HC} 2$ also genotype 66 . Cross-reacting samples exhibited relatively weak signal strengths, and few were associated with $\geq$ CIN2. Cross-reactivity to low-risk genotypes was more frequent in young women, in abnormal cytology, and after previous abnormalities. Cross-reactivity to unconfirmed genotypes, on the other hand, tended to be more frequent in normal cytology. There were only a few samples that cross-reacted on all three assays, suggesting that cross-reactivity is driven by technology.

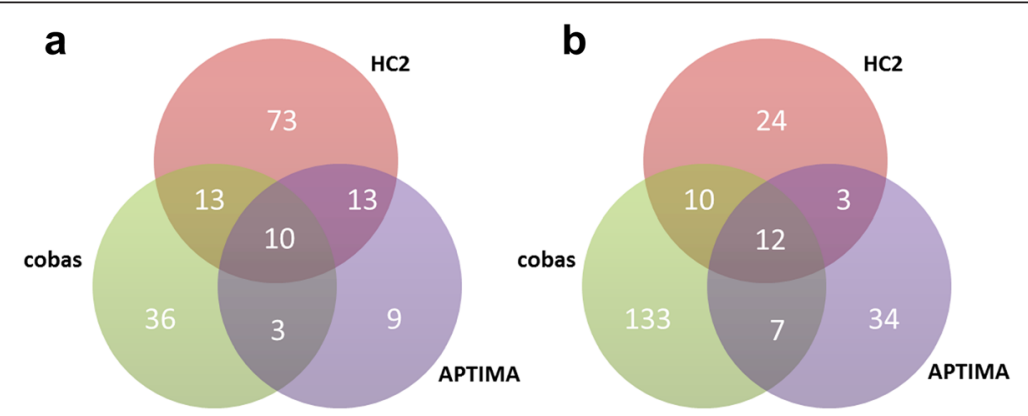

Fig. 1 Inter-assay distribution of samples cross-reacting to low-risk genotypes $\mathbf{a}$ and unconfirmed genotypes $\mathbf{b}$ 
Table 3 Women with CIN2 or higher: Screening test results for cross-reacting samples

\begin{tabular}{|c|c|c|c|c|c|c|}
\hline \multirow[b]{2}{*}{ Case number } & \multirow[b]{2}{*}{ Grade of CIN } & \multirow[b]{2}{*}{ Cytology } & \multirow[b]{2}{*}{$\begin{array}{l}\text { Detected genotypes } \\
\text { by CLART }\end{array}$} & \multicolumn{3}{|l|}{ HPV test result } \\
\hline & & & & $\begin{array}{l}\mathrm{HC2} \text {, relative light } \\
\text { units per cut-off }\end{array}$ & cobas, cycle threshold & $\begin{array}{l}\text { APTIMA, signal per } \\
\text { cut-off }\end{array}$ \\
\hline \multicolumn{7}{|c|}{ Cross-reactivity to low-risk genotypes } \\
\hline 1 & Grade 2 & Atypical & $70,71,81,84$ & $\begin{array}{l}\text { Positive } \\
\text { (cross-reacting), } 9.55\end{array}$ & Negative & $\begin{array}{l}\text { Positive } \\
\text { (cross-reacting), } 3.44\end{array}$ \\
\hline 2 & Grade 2 & Normal & $53,66,83$ & $\begin{array}{l}\text { Positive } \\
\text { (cross-reacting), } 3.58\end{array}$ & $\begin{array}{l}\text { Positive, other high-risk } \\
\text { genotypes: } 30.1\end{array}$ & Negative \\
\hline 3 & Grade 3 & Low-grade & 82 & $\begin{array}{l}\text { Positive } \\
\text { (cross-reacting), } 2.70\end{array}$ & $\begin{array}{l}\text { Positive (cross-reacting), } \\
\text { genotype } 16: 37.3\end{array}$ & Negative \\
\hline 4 & Grade 3 & High-grade & 42,61 & $\begin{array}{l}\text { Positive } \\
\text { (cross-reacting), } 5.74\end{array}$ & Negative & Negative \\
\hline 5 & Grade 3 & High-grade & 82 & $\begin{array}{l}\text { Positive } \\
\text { (cross-reacting), } 11.06\end{array}$ & Negative & Negative \\
\hline 6 & Cervical cancer & High-grade & 70 & $\begin{array}{l}\text { Positive } \\
\text { ("cross-reacting"), } 21.43\end{array}$ & $\begin{array}{l}\text { Positive ("cross-reacting"), } \\
\text { genotype 18: } 39.5\end{array}$ & $\begin{array}{l}\text { Positive } \\
\text { ("cross-reacting"), } 0.84\end{array}$ \\
\hline \multicolumn{7}{|c|}{ Cross-reactivity to unconfirmed genotypes } \\
\hline 7 & Grade 3 & Atypical & None & $\begin{array}{l}\text { Positive } \\
\text { (CLART negative), } 2.14\end{array}$ & $\begin{array}{l}\text { Positive (CLART negative), } \\
\text { other high-risk genotypes: } 34.0\end{array}$ & $\begin{array}{l}\text { Positive } \\
\text { (CLART negative), } 14.92\end{array}$ \\
\hline
\end{tabular}

\section{Strengths and weaknesses}

This is the first study that systematically evaluated cross-reactivity on three widely used assays in a splitsample study. It is, furthermore, the first independent study on cobas and APTIMA. We used consecutive, unselected, samples from women undergoing routine screening or follow-up of abnormalities. All testing was undertaken in the same laboratory by the same staff. This split-sample design helped eliminate variability in study populations and laboratory performance. Samples

Table 4 Breakdown of positive and negative test results on HC2, cobas, and APTIMA, by the number and risk level of HPV genotypes detected on CLART

\begin{tabular}{|c|c|c|c|c|c|c|c|c|c|c|}
\hline \multirow{2}{*}{$\begin{array}{l}\text { Risk level of detected } \\
\text { genotypes }\end{array}$} & \multirow{2}{*}{$\begin{array}{l}\text { Number of } \\
\text { genotypes }\end{array}$} & \multicolumn{3}{|l|}{$\mathrm{HC2}$} & \multicolumn{3}{|l|}{ cobas } & \multicolumn{3}{|l|}{ APTIMA } \\
\hline & & $\begin{array}{l}\text { Negative test } \\
\text { result }\end{array}$ & $\begin{array}{l}\text { Positive test } \\
\text { result }\end{array}$ & Total & $\begin{array}{l}\text { Negative test } \\
\text { result }\end{array}$ & $\begin{array}{l}\text { Positive test } \\
\text { result }\end{array}$ & Total & $\begin{array}{l}\text { Negative test } \\
\text { result }\end{array}$ & $\begin{array}{l}\text { Positive test } \\
\text { result }\end{array}$ & Total \\
\hline \multirow[t]{5}{*}{ Only low-risk } & 1 & $410(84 \%)$ & 79 (16 \%) & 489 & 390 (89 \%) & $47(11 \%)$ & 437 & $412(94 \%)$ & 25 (6 \%) & 437 \\
\hline & 2 & $72(80 \%)$ & $18(20 \%)$ & 90 & $66(85 \%)$ & $12(15 \%)$ & 78 & $73(94 \%)$ & $5(6 \%)$ & 78 \\
\hline & 3 & 18 (69 \%) & 8 (31 \%) & 26 & $16(84 \%)$ & $3(16 \%)$ & 19 & 16 (84 \%) & $3(16 \%)$ & 19 \\
\hline & $\geq 4$ & $6(60 \%)$ & 4 (40 \%) & 10 & 10 (100\%) & $0(0 \%)$ & 10 & 8 (80 \%) & 2 (20 \%) & 10 \\
\hline & Total & 506 (82 \%) & 109 (18\%) & 615 & 482 (89 \%) & $62(11 \%)$ & 544 & 509 (94 \%) & 35 (6 \%) & 544 \\
\hline \multirow[t]{5}{*}{ Only high-risk } & 1 & $245(50 \%)$ & $242(50 \%)$ & 487 & $143(27 \%)$ & 396 (73 \%) & 539 & 319 (59\%) & $220(41 \%)$ & 539 \\
\hline & 2 & 19 (10 \%) & 169 (90\%) & 188 & $8(5 \%)$ & 146 (95\%) & 153 & 45 (29 \%) & 109 (71 \%) & 153 \\
\hline & 3 & $3(6 \%)$ & $45(94 \%)$ & 48 & $1(2 \%)$ & $53(98 \%)$ & 54 & $13(24 \%)$ & 41 (76 \%) & 54 \\
\hline & $\geq 4$ & $0(0 \%)$ & $12(100 \%)$ & 12 & $0(0 \%)$ & 18 (100 \%) & 17 & $1(6 \%)$ & 17 (94%) & 17 \\
\hline & Total & 267 (36 \%) & 468 (64 \%) & 735 & $152(20 \%)$ & 613 (80 \%) & 765 & 378 (49 \%) & 387 (51 \%) & 765 \\
\hline \multirow[t]{4}{*}{ Low-risk and high-risk } & 2 & $72(46 \%)$ & 86 (54 \%) & 158 & $42(20 \%)$ & 162 (79 \%) & 205 & 106 (52 \%) & $98(48 \%)$ & 205 \\
\hline & 3 & $38(25 \%)$ & 116 (75 \%) & 154 & $16(10 \%)$ & 139 (90 \%) & 155 & $56(36 \%)$ & 99 (64 \%) & 155 \\
\hline & $\geq 4$ & 19 (9 \%) & 196 (91%) & 215 & $2(1 \%)$ & 207 (99\%) & 210 & 46 (22 \%) & 163 (78 \%) & 210 \\
\hline & Total & 129 (24 \%) & 398 (76 \%) & 527 & $60(11 \%)$ & 508 (89 \%) & 568 & 208 (37 \%) & 360 (63\%) & 568 \\
\hline No genotypes & 0 & 3096 (98 \%) & $49(2 \%)$ & 3145 & 2981 (95\%) & $162(5 \%)$ & $3143^{a}$ & $3089(98 \%)$ & $56(2 \%)$ & 3145 \\
\hline Total & - & - & - & 5022 & - & - & $5020^{a}$ & - & - & 5022 \\
\hline
\end{tabular}

a Two samples had an invalid test result on cobas. For both samples, HC2 and APTIMA test results were negative; CLART detected no genotypes; cytology on one sample was normal, and inadequate on the other sample 


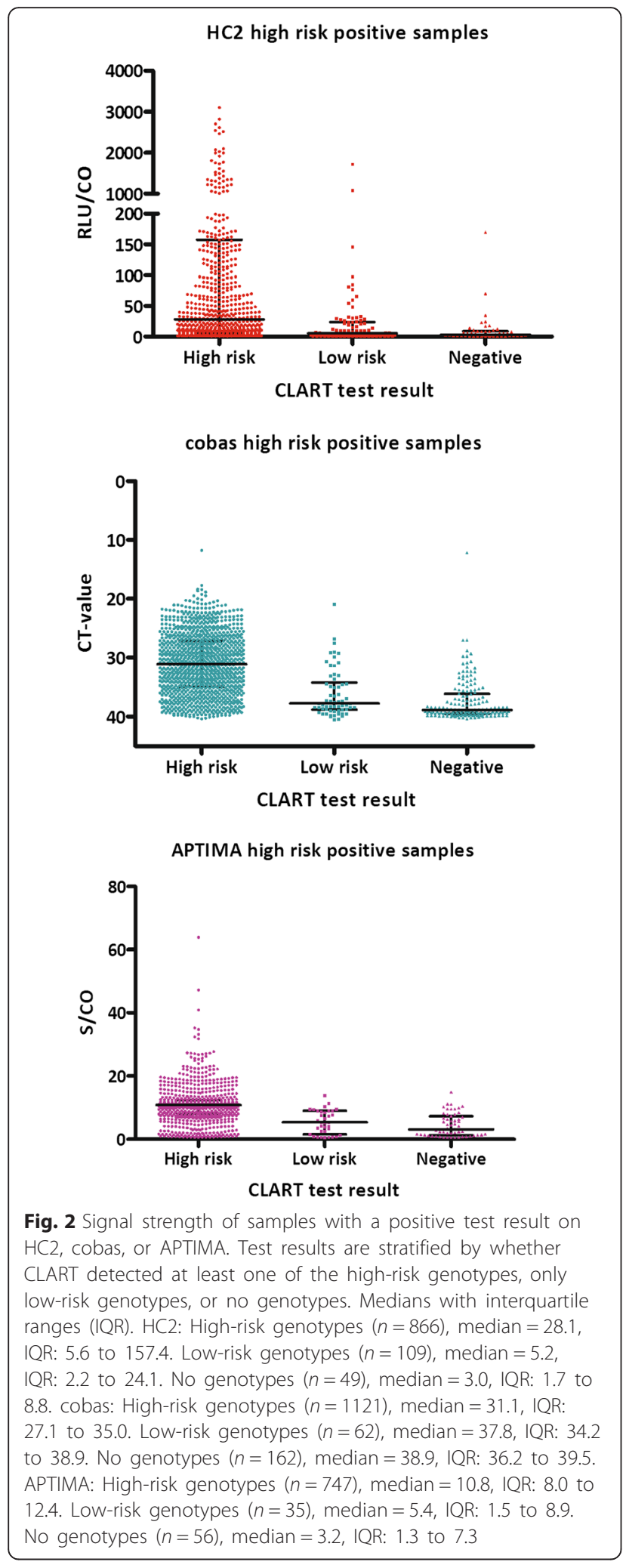

were stored in SurePath, a liquid-based cytology medium that is frequently used in Europe and the USA. Samples were heated to reverse the covalent bindings between genomic material and protein complexes induced by SurePath's formaldehyde. This procedure renders the genetic material accessible for analysis [22]. We could determine the reason for sampling, enabling us to compare the frequency of cross-reactivity in the primary screening and referral populations. In line with our previous analyses [17], we again conclude that the data from referral populations cannot be generalised to the primary screening context.

Biological material can deteriorate or disintegrate upon storage. Prolonged storage could impact the data especially in samples with weak signal strength, a characteristic we observed in cross-reacting samples. Thus, using fresh samples, as we did in our study $[12,14,16]$, may be the only reliable way to evaluate and compare the frequency of cross-reactivity. Moreover, in concordance with the protocol and by approval from the manufacturers, we diluted the original samples approximately $1: 1$. This can be seen as a weakness. However, all three assays rely on testing aliquots of $0.5-1 \mathrm{ml}$ out of the typically 10 (SurePath) or $20 \mathrm{ml}$ (ThinPrep) available from liquid-based cytology media. Hence, assay designs should be robust enough to handle sampling variability in terms of cellularity.

There is no internationally agreed standard genotyping assay, so the choice of a reference assay can be discussed [7, 11]. No HPV assay, with or without genotyping, seems to detect all targeted infections [17, 23]. CLART is a CE-IVD marked assay, not "research use only", and is currently used in a number of regional European screening programmes. It has been evaluated in clinical settings [12, 24-28], and its analytical performance has been compared to, for example, linear array (LA) as part of the latest WHO HPV LabNet Proficiency Studies [29]. There, both assays showed a high analytical sensitivity for genotypes 16 and 18, even at low plasmid concentrations. CLART more often correctly detected genotypes $6,11,31$, $33,35,51,52,58,59$, and 66 compared to LA, but the latter was better at detecting genotypes 45 and 56 at high plasmid concentrations. Finally, we chose CLART as a reference assay given that it reports the detected genotypes using a computer algorithm rather than manual reading. This enables a more reproducible and objective assay read-out.

In this study, CLART detected high-risk genotypes or genotype 66 in $27 \%$ of all samples. This was comparable to the proportion in which cobas detected high-risk genotypes (27\%), and higher than the proportions detected by $\mathrm{HC} 2(20 \%)$ and APTIMA (17\%). In a different study from our laboratory using data from 401 women with abnormal cytology [28], we also compared the detection of low-risk genotypes between CLART and LA. The detection of several genotypes found to be most frequently cross-reacting in the present study $(53,61,66$, and 70$)$ was very similar, with an overall agreement of 98-99 \%. For 
the other two most frequently cross-reacting genotypes (62 and 82), the level of agreement was slightly lower (96 and $93 \%$, respectively).

However, a general limitation of CLART is the relatively long amplicons generated from the modified PGMY09/11 primers, meaning that partially complete amplicons or unspecific amplifications are less likely to be reported as positive test findings compared to genotyping assays relying on shorter amplicons, such as LA. Furthermore, in our study CLART detected only a genotype 70 infection in one case of cervical cancer associated where cobas detected genotype 18 [15]. A CIN3 case was positive on all three evaluated assays but negative on CLART. The remaining five cases of $\mathrm{CIN} 2 / 3$ that were apparently missed by CLART were positive only on one or two of the evaluated assays. Given that the histology was read under routine circumstances, false-positive histology findings cannot be entirely ruled out [8].

Finally, the cross-reactivity estimates for APTIMA should be interpreted with respect to the fact that it detects HPV mRNA, whereas CLART detects HPV DNA. Therefore, APTIMA should ideally have been evaluated against an mRNA genotyping assay. However, no such assay exists.

\section{Comparison with the literature}

Castle et al. [6] studied cross-reactivity patterns of $\mathrm{HC} 2$ probe B against the combined test results of MY09/11 Amplitaq DNA polymerase and Amplitaq Gold DNA polymerase in an unscreened population $(n=954)$. Of all single low-risk genotype infections, $\mathrm{HC} 2$ cross-reacted in $20 \%$, most frequently because of genotypes 11,53 , $61,66,67,70,71$, and 81 . Six (6\%) of $108 \geq \mathrm{CIN} 3$ were detected in cross-reacting samples, and 5 (5\%) in samples with no detected genotypes. In normal cytology, cross-reacting samples increased the sensitivity for highgrade CIN, whereas in abnormal cytology, they primarily decreased the specificity. Very similar results were found in the ALTS trial, using archived samples (collected in STM media or PreservCyt) from 3179 women with ASCUS/LSIL [7]. Cross-reactivity, assessed against the combined test results of line blot (a prototype for LA) and LA assays, was observed in $8 \%$ of samples with a positive $\mathrm{HC} 2$ test result (4\% of all samples), whereas $2 \%(1 \%)$ had no detected genotypes on the reference assays. The most frequently involved genotypes were 66, 70 , and 82 , and the likelihood of cross-reactivity increased in multiple low-risk infections. Cross-reacting samples had weaker signals than samples with high-risk

Table 5 Genotype distribution in samples cross-reacting to low-risk genotypes

\begin{tabular}{|c|c|c|c|c|c|c|c|c|}
\hline \multirow[t]{2}{*}{ Genotype } & \multirow{2}{*}{$\begin{array}{l}\text { Phylogenetic } \\
\text { clade }\end{array}$} & \multirow{2}{*}{$\begin{array}{l}\text { High-risk genotypes } \\
\text { in the same } \\
\text { phylogenetic clade }\end{array}$} & \multicolumn{2}{|l|}{$\mathrm{HC} 2$} & \multicolumn{2}{|l|}{ cobas } & \multicolumn{2}{|l|}{ APTIMA } \\
\hline & & & $\begin{array}{l}\text { Single } \\
\text { infections (\%) }\end{array}$ & $\begin{array}{l}\text { Multiple } \\
\text { infections (\%) }\end{array}$ & $\begin{array}{l}\text { Single } \\
\text { infections (\%) }\end{array}$ & $\begin{array}{l}\text { Multiple } \\
\text { infections (\%) }\end{array}$ & $\begin{array}{l}\text { Single } \\
\text { infections (\%) }\end{array}$ & $\begin{array}{l}\text { Multiple } \\
\text { infections (\%) }\end{array}$ \\
\hline 6 & a10 & None & $2(2.5 \%)$ & $5(6.6 \%)$ & $3(6.4 \%)$ & $4(12.1 \%)$ & $0(0.0 \%)$ & $2(7.4 \%)$ \\
\hline 11 & a10 & None & $0(0.0 \%)$ & $0(0.0 \%)$ & $1(2.1 \%)$ & $0(0.0 \%)$ & $0(0.0 \%)$ & $0(0.0 \%)$ \\
\hline 26 & a5 & 51 & $0(0.0 \%)$ & $0(0.0 \%)$ & $1(2.1 \%)$ & $0(0.0 \%)$ & $0(0.0 \%)$ & $0(0.0 \%)$ \\
\hline 42 & a1 & None & $5(6.3 \%)$ & $3(3.9 \%)$ & $4(8.5 \%)$ & $0(0.0 \%)$ & $2(8.0 \%)$ & $2(7.4 \%)$ \\
\hline 44 & a10 & None & $0(0.0 \%)$ & $3(3.9 \%)$ & $0(0.0 \%)$ & 2 (6.1\%) & $0(0.0 \%)$ & $0(0.0 \%)$ \\
\hline 53 & $a 6$ & 56 & 14 (17.7 \%) & 10 (13.2 \%) & $4(8.5 \%)$ & 4 (12.1\%) & $0(0.0 \%)$ & 2 (7.4 \%) \\
\hline 54 & a13 & None & $2(2.5 \%)$ & $2(2.6 \%)$ & $2(4.3 \%)$ & 2 (6.1\%) & $0(0.0 \%)$ & 1 (3.7 \%) \\
\hline 61 & a3 & None & $2(2.5 \%)$ & 7 (9.2 \%) & 7 (14.9\%) & 4 (12.1\%) & $3(12.0 \%)$ & 1 (3.7\%) \\
\hline 62 & a3 & None & $2(2.5 \%)$ & $5(6.6 \%)$ & $4(8.5 \%)$ & 2 (6.1\%) & $4(16.0 \%)$ & 3 (11.1\%) \\
\hline 66 & $a 6$ & 56 & 16 (20.3 \%) & 8 (10.5 \%) & Not relevant & Not relevant & Not relevant & Not relevant \\
\hline 70 & $a 7$ & $18,39,45,59,68$ & 15 (19.0\%) & 8 (10.5 \%) & 9 (19.1%) & 3 (9.1\%) & 9 (36.0 \%) & 4 (14.8 \%) \\
\hline 71 & a15 & None & $0(0.0 \%)$ & $1(1.3 \%)$ & $0(0.0 \%)$ & $0(0.0 \%)$ & $0(0.0 \%)$ & $1(3.7 \%)$ \\
\hline 72 & a3 & None & $0(0.0 \%)$ & $1(1.3 \%)$ & $0(0.0 \%)$ & $1(3.0 \%)$ & $0(0.0 \%)$ & 1 (3.7\%) \\
\hline 73 & a11 & None & 1 (1.3 \%) & 2 (2.6 \%) & $0(0.0 \%)$ & $0(0.0 \%)$ & $0(0.0 \%)$ & 1 (3.7 \%) \\
\hline 81 & a3 & None & 3 (3.8 \%) & $4(5.3 \%)$ & $3(6.4 \%)$ & 2 (6.1\%) & $1(4.0 \%)$ & 2 (7.4 \%) \\
\hline 82 & a5 & 51 & 11 (13.9\%) & 5 (6.6 \%) & $3(6.4 \%)$ & 2 (6.1\%) & $3(12.0 \%)$ & $2(7.4 \%)$ \\
\hline 83 & a3 & None & $2(2.5 \%)$ & 7 (9.2 \%) & $3(6.4 \%)$ & 3 (9.1\%) & 3 (12.0 \%) & $2(7.4 \%)$ \\
\hline 84 & a3 & None & $4(5.1 \%)$ & $5(6.6 \%)$ & $3(6.4 \%)$ & 4 (12.1\%) & $0(0.0 \%)$ & 3 (11.1\%) \\
\hline \# Genotypes & - & - & 79 (100 \%) & 76 (100 \%) & 47 (100 \%) & 33 (100 \%) & 25 (100 \%) & 27 (100 \%) \\
\hline \# Samples & - & - & 79 & 30 & 47 & 15 & 25 & 10 \\
\hline
\end{tabular}

No woman had a cross-reacting sample on any of the three HPV assays because of genotypes 40 ( $a 8$ ), 43 (a8), 85 ( $\alpha 7$ ), or 89 ( $(\alpha 3)$ 
Table 6 Genotype distribution in cross-reacting samples on cobas

\begin{tabular}{|c|c|c|c|c|c|c|c|c|}
\hline \multirow[t]{2}{*}{ Genotype } & \multicolumn{8}{|c|}{ cobas test result } \\
\hline & Genotype 16 & Genotype 18 & $\begin{array}{l}\text { Other high-risk } \\
\text { genotypes }\end{array}$ & 16 and 18 & $\begin{array}{l}16 \text { and other } \\
\text { high-risk }\end{array}$ & $\begin{array}{l}18 \text { and other } \\
\text { high-risk }\end{array}$ & $\begin{array}{l}16,18 \text {, and } \\
\text { other high-risk }\end{array}$ & Total \\
\hline 6 & 1 & 0 & 6 & 0 & 0 & 0 & 0 & 7 \\
\hline 11 & 0 & 0 & 1 & 0 & 0 & 0 & 0 & 1 \\
\hline 26 & 0 & 0 & 1 & 0 & 0 & 0 & 0 & 1 \\
\hline 42 & 2 & 0 & 2 & 0 & 0 & 0 & 0 & 4 \\
\hline 44 & 0 & 0 & 2 & 0 & 0 & 0 & 0 & 2 \\
\hline 53 & 0 & 1 & 7 & 0 & 0 & 0 & 0 & 8 \\
\hline 54 & 1 & 1 & 2 & 0 & 0 & 0 & 0 & 4 \\
\hline 61 & 3 & 1 & 7 & 0 & 0 & 0 & 0 & 11 \\
\hline 62 & 0 & 0 & 6 & 0 & 0 & 0 & 0 & 6 \\
\hline 70 & 0 & 2 & 10 & 0 & 0 & 0 & 0 & 12 \\
\hline 72 & 0 & 0 & 1 & 0 & 0 & 0 & 0 & 1 \\
\hline 81 & 1 & 0 & 3 & 0 & 0 & 1 & 0 & 5 \\
\hline 82 & 1 & 0 & 4 & 0 & 0 & 0 & 0 & 4 \\
\hline 83 & 0 & 0 & 6 & 0 & 0 & 0 & 0 & 6 \\
\hline 84 & 0 & 0 & 6 & 0 & 1 & 0 & 0 & 7 \\
\hline $\begin{array}{l}\text { \# Samples with a positive test } \\
\text { result }\end{array}$ & 168 (100 \%) & $56(100 \%)$ & 858 (100\%) & $6(100 \%)$ & 167 (100 \%) & $71(100 \%)$ & 19 (100\%) & $1345(100 \%)$ \\
\hline $\begin{array}{l}\text { \# Samples with only low-risk } \\
\text { genotypes }\end{array}$ & 8 (4.8\%) & $4(7.1 \%)$ & 48 (5.6 \%) & $0(0.0 \%)$ & 1 (0.6 \%) & 1 (1.4\%) & $0(0.0 \%)$ & $62(4.6 \%)$ \\
\hline $\begin{array}{l}\text { \# Samples with no detected } \\
\text { genotype }\end{array}$ & 26 (15.5\%) & 10 (17.9\%) & 116 (13.5\%) & $0(0.0 \%)$ & 8 (4.8\%) & 2 (2.8\%) & 0 (0.0\%) & $162(12.0 \%)$ \\
\hline
\end{tabular}

No woman had a cross-reacting sample on cobas because of genotypes $40,43,71,73,85$, or 89

Table 7 Effect of cross-reactivity on the proportion of women with positive and false-positive HPV test results

\begin{tabular}{|c|c|c|c|c|c|c|}
\hline & \multicolumn{2}{|l|}{$\mathrm{HC2}$} & \multicolumn{2}{|l|}{ cobas } & \multicolumn{2}{|l|}{ APTIMA } \\
\hline & $N(\%)$ & $\geq \mathrm{CIN} 2$ & $N(\%)$ & $\geq \mathrm{CIN} 2$ & $N(\%)$ & $\geq \mathrm{CIN} 2$ \\
\hline \multicolumn{7}{|l|}{ Primary screening, $30-65$ years $(n=2859)$} \\
\hline All positive test results & $335(11.7 \%)$ & 46 & $464(16.2 \%)$ & 49 & $270(9.4 \%)$ & 46 \\
\hline Samples with high-risk genotypes & $262(9.2 \%)$ & 45 & $357(12.5 \%)$ & 48 & $221(7.7 \%)$ & 45 \\
\hline Cross-reacting samples & $73(2.6 \%)$ & 1 & 107 (3.7\%) & 1 & $49(1.7 \%)$ & 1 \\
\hline False-positive test results, all (\%) & $289(10.1 \%)$ & - & $415(14.5 \%)$ & - & $224(7.8 \%)$ & - \\
\hline False-positive test results, after exclusion of cross-reactivity (\%) & $217(7.6 \%)$ & - & $309(10.8 \%)$ & - & $176(6.2 \%)$ & - \\
\hline Proportion of false-positive test results due to cross-reactivity & $25 \%$ & - & $26 \%$ & - & $21 \%$ & - \\
\hline \multicolumn{7}{|l|}{ Referral population $(n=887)$} \\
\hline All positive test results & $401(45.2 \%)$ & 124 & $453(51.1 \%)$ & 123 & $332(37.4 \%)$ & 112 \\
\hline Samples with high-risk genotypes & $345(38.9 \%)$ & 117 & $410(46.2 \%)$ & 120 & $316(35.6 \%)$ & 109 \\
\hline Cross-reacting samples & $56(6.3 \%)$ & 7 & $43(4.8 \%)$ & 3 & $16(1.8 \%)$ & 3 \\
\hline False-positive test results, all (\%) & $277(31.2 \%)$ & - & $330(37.2 \%)$ & - & $220(24.8 \%)$ & - \\
\hline False-positive test results, after exclusion of cross-reactivity (\%) & $228(25.7 \%)$ & - & $290(32.7 \%)$ & - & $207(23.3 \%)$ & - \\
\hline Proportion of false-positive test results due to cross-reactivity & $18 \%$ & - & $12 \%$ & - & $6 \%$ & - \\
\hline
\end{tabular}


genotypes. Out of $272 \geq \mathrm{CIN} 3$, three $(1 \%)$ were from women with cross-reacting samples, and one $(<1 \%)$ from a woman with no detected genotypes. In a Guanacaste vaccination trial of women aged 18-25 years, Safaeian et al. [10] evaluated cross-reactivity of HC2 on ThinPrep samples against a highly analytically sensitive SPF-10 assay. While genotype 66 was not included in the analysis, 70 and 53 were most frequently involved in cross-reactivity. Low amounts of viral target input material and younger age were associated with crossreactivity.

In the UK HPV screening trial ARTISTIC, Sargent et al. found very high proportions of cross-reacting samples at 20-64 years [11]. Of the $3773 \mathrm{HC} 2$-positive ThinPrep samples, line blot assay detected only low-risk genotypes in $11 \%$ (predominantly 53,66 , and 70 ), and no genotypes in additional $20 \%$. In approximately half of these samples, the signal strength was low, between 1 and 2 RLU/CO. In the Italian HPV screening trial NTCC, Gillio-Tos et al. [8] genotyped HC2-positive ThinPrep samples at 25-60 years using GP5+/GP6+ PCR with reverse line blot hybridisation, and, if no genotypes were found, also restriction fragment length polymorphism testing and sequencing. Relative crossreactivity was $14 \%$ (most frequently because of genotypes 66, 70, and 53), whereas in $7 \%$ of $\mathrm{HC} 2$-positive samples no HPV DNA was detected. They suggested a role of the collection medium, and reported a higher probability of cross-reactivity for ThinPrep than for Specimen Transport Medium.

Overall, previous studies evaluated cross-reactivity for HC2 against a variety of genotyping assays, of which some were research versions and some have been discontinued. Several studies were undertaken on frozen samples stored in various sampling media. Nevertheless, our data are in line with previous observations. Independent evaluations of cross-reactivity for cobas and APTIMA have not been reported elsewhere, and as such represent valuable information for decision makers in choosing assays for screening purposes.

\section{Clinical and technical implications}

Of the 175 CIN2/3 in our study, seven (4\%) were associated with cross-reactivity. The question is whether their detection and treatment prevented cervical cancer. It could be hypothesised that these cases were likely regressive. However, treatment of all high-grade CIN is recommended in Denmark, so this hypothesis cannot be evaluated using our data. For HC2, cross-reactivity to genotype 66 played an important role. Of all 52 single infections with this genotype, HC2 detected 16 (31 \%). APTIMA and cobas were designed to detect this genotype. Yet, cobas detected only 31 (60\%), and APTIMA 11 (21\%) single-genotype 66 infections. Nevertheless, given that genotype 66 probably does not cause cervical cancer [5], the relatively inconsistent detection of this genotype unintentionally improves the clinical specificity of the two assays.

We propose three scenarios that may have contributed to cross-reactivity. Firstly, cross-reactivity to low-risk genotypes may have been generated by sequence homology in the assay amplification target region, whether that was $L 1$ (cobas), E6/E7 (APTIMA), or whole HPV genome (HC2). In our data, all three assays showed rather extensive cross-reactivity to genotype 70 . Genotype 70 shares phylogenetic clade $(\alpha 7)$ with genotype 18 . The latter is associated with adenocarcinomas and typically causes lesions characterised by low viral loads compared to e.g. genotype 16 [30-33]. It seems plausible that the assays may have been calibrated to detect genotype 18 , but with an unintentional drawback of picking up sameclade low-risk genotypes. Within this context, the frequent cross-reactivity of $\mathrm{HC} 2$ to genotypes 53 and 66, and occasional cross-reactivity to genotypes 26 and 82, might be attributable to the fact that they share clades $(\alpha 5, \alpha 6)$ with high-risk genotypes 51 and 56.

Secondly, cross-reactivity may have been caused by detection of non-specific, incomplete amplicons or by signal amplification probes hybridising to non-target sequences. Incomplete or unspecific amplifications would not hybridise efficiently to the array probes. When using technologies such as CLART with separate amplification and detection processes, this would most likely lead to detection of no genotype.

Thirdly, cross-reactivity may be generated by another aspect of the assays' technical designs, in that specific or non-specific amplifications, otherwise below the positivity threshold, add up to push the total signal value above the manufacturer's cut-off. This additive signal effect might explain the relatively high likelihood of cross-reactivity observed among younger women and women with abnormalities, as they tend to harbour the highest numbers of multiple infections. Consequently, assays with fewer genotype targets per channel or read-out could be speculated to be more precise from the analytical perspective, making the case for assays with genotyping beyond that of an individual detection of only genotypes 16 and 18 .

\section{Conclusions}

$\mathrm{HC} 2$, cobas and APTIMA all showed cross-reactivity which seemed to be driven primarily by the assays' designs. A quarter of all false-positive test results in primary screening at $\geq 30$ years cross-reacted. To obtain improved analytical and clinical performance, cross-reactivity should be addressed by optimising the assays. For now, crossreactivity should be addressed in EU tenders, as this primarily technical shortcoming imposes additional costs on the screening programmes as well as risking the public's view on the effectiveness of cervical screening. 


\section{Abbreviations}

ASCUS, Atypical squamous cells of undetermined significance; CIN, Cervical intraepithelial neoplasia; $\mathrm{CT}$, Cycle threshold; HC2, hybrid capture II; HPV, Human papillomavirus; IQR, Interquartile range; LBC, Liquid based cytology; PCR, Polymerase chain reaction; RLU/CO, Relative light units/cut-off; S/CO, Signal/cut-off; STM, Specimen transport medium

\section{Acknowledgments}

The authors would like to thank the women for their participation in the followup. They would, furthermore, like to thank Maria-Louise Deistler and Miki Hansen for their expert laboratory assistance. Finally, the authors would like to acknowledge the Danish Genomica, QIAGEN, Roche and Hologic/Gen-Probe representatives for enabling the collaboration between their parent company and Copenhagen University Hospital, Hvidovre and University of Copenhagen.

\section{Funding}

Genomica, the manufacturer of the CLART HPV2 Assay; Hologic/Gen-Probe, the manufacturer of the APTIMA HPV Assay; Roche, the manufacturer of the cobas HPV Test; and QIAGEN, the manufacturer of the HC2 Assay, provided tests, instrumentation, and limited co-funding for laboratory material. According to the contract between the manufacturers, Copenhagen University Hospital Hvidovre, and University of Copenhagen, all four manufacturers had the right to comment on a draft version of this manuscript, but had no editorial rights. MR and SP were funded by the Danish Strategic Research Council (grant number: 10-092793; URL: http://fivu.dk/en/research-and-innovation/councils-and-commissions/the-danishcouncil-for-strategic-research). The funders had no role in study design, data collection and analysis, decision to publish, or preparation of the manuscript. The researchers worked independently of the funders.

\section{Availability of data and materials}

Original data from this study is not available for deposition in online repositories, as it would violate the study approval from the Danish Data Protection Agency.

\section{Authors' contributions}

JB designed the study. SP, DME and JB performed the laboratory work. SP, MR and JB did the analysis of the data and drafted the manuscript. SP, MR, DME, EL, $C R$ and JB interpreted the results, did critical revision of the manuscript and decided to submit. SP, MR, DME, EL, CR and JB had full access to all of the data in the study. MR and JB are the guarantors. All authors read and approved the final manuscript.

\section{Competing interests}

All authors have attended meetings with manufacturers of HPV assays and utensils. SP received honoraria from Hologic for lectures. MR and her former employer received honoraria from QIAGEN for lectures on her behalf. DME received honoraria from Genomica and QIAGEN for lectures, and is project manager on a study financed by BD Diagnostics. EL was an unpaid advisor to Hologic and Norchip. CR was an unpaid advisor to Roche. JB was a paid advisor to Roche and Genomica, received honoraria from Hologic, Roche, QIAGEN, Genomica, and BD Diagnostics for lectures, and is principal investigator on a study financed by BD. None of the authors was compensated for their work on this project, holds stock, or received bonuses from any of the manufacturers. Copenhagen University Hospital Hvidovre holds a recompense agreement with Genomica on a KRAS/BRAF oncology diagnostic system.

\section{Consent for publication}

Not applicable.

\section{Ethics approval and consent to participate}

The Horizon Study was designed as a quality development study in concordance with $\S 42$ s. 3 of the Danish Health Care Act (Sundhedsloven), utilizing only residual material that would otherwise have been discarded. According to Danish regulations of biomedical research, published on 5 May 2011 in the Guidelines about Notification etc. of a Biomedical Research Project to the Committee System on Biomedical Research Ethics No. 9154 section 2.5, quality development studies do not require ethical approval, and informed consent did not need to be sought from the participants. The legal office of the Ethical Committee of Capital Region, Denmark, reviewed the study protocol prior to the initiation of the study. Invitation to follow-up of HPV-positive/cytology-normal women was separately approved by the
Ethical Committee of the Danish Capital Region (H-4-2012-120) and women had to sign informed consent. The study was notified to the Danish Data Inspection Agency (notification number 2010-41-5594).

\section{Author details}

${ }^{1}$ Clinical Research Centre and Department of Pathology, Copenhagen University Hospital Hvidovre, Kettegård Allé 30, 2650 Hvidovre, Denmark. ${ }^{2}$ Department of Pathology, Copenhagen University Hospital Hvidovre, Kettegård Allé 30, 2650 Hvidovre, Denmark. 'Department of Public Health, University of Copenhagen, Øster Farimagsgade 5, 1014 Copenhagen K, Denmark.

Received: 16 September 2015 Accepted: 28 June 2016

Published online: 20 July 2016

\section{References}

1. NHS Cervical Screening Programme. HPV triage and test of cure in the cervical screening programme in England. http://www.cancerscreening.nhs. uk/cervical/hpv-triage-test-of-cure.html. Accessed 12 August 2015.

2. NHS Cervical Screening Programme. HPV primary screening in the NHS Cervical Screening Programme. http://www.cancerscreening.nhs.uk/cervical/ hpv-primary-screening.html Accessed 12 August 2015

3. Huh WK. Use of primary high-risk human papillomavirus testing for cervical cancer screening: interim clinical guidance. Gynecol Oncol. 2015;136(2):178-82.

4. Ronco G, Dillner J, Elfström KM, Tunesi S, Snijders PJF, Arbyn M et al. Efficacy of HPV-based screening for prevention of invasive cervical cancer: follow-up of four European randomised controlled trials. The Lancet. 2014;383(9916): 524-32. doi:http://dx.doi.org/10.1016/S0140-6736(13)62218-7.

5. Bouvard V, Baan R, Straif K, Grosse Y, Secretan B, El Ghissassi F, et al. A review of human carcinogens-part B: biological agents. Lancet Oncol. 2009; 10(4):321-2.

6. Castle PE, Schiffman M, Burk RD, Wacholder S, Hildesheim A, Herrero R, et al Restricted cross-reactivity of hybrid capture 2 with nononcogenic human papillomavirus types. Cancer Epidemiol Biomarkers Prev. 2002;11(11):1394-9.

7. Castle PE, Solomon D, Wheeler CM, Gravitt PE, Wacholder S, Schiffman M. Human papillomavirus genotype specificity of hybrid capture 2. J Clin Microbiol. 2008;46(8):2595-604. doi:10.1128/JCM.00824-08.

8. Gillio-Tos A, De Marco L, Carozzi FM, Del Mistro A, Girlando S, Burroni E, et al. Clinical Impact of the Analytical Specificity of the Hybrid Capture 2 Test: Data from the New Technologies for Cervical Cancer (NTCC) Study. J Clin Microbiol. 2013;51(9):2901-7. doi:10.1128/jcm.01047-13.

9. Poljak M, Marin IJ, Seme K, Vince A. Hybrid capture II HPV test detects at least 15 human papillomavirus genotypes not included in its current highrisk probe cocktail. J Clin Virol. 2002;25 Suppl 3:S89-97.

10. Safaeian M, Herrero R, Hildesheim A, Quint W, Freer E, Van Doorn $\sqcup$, et al. Comparison of the SPF10-LiPA system to the hybrid capture 2 assay for detection of carcinogenic human papillomavirus genotypes among 5,683 young women in guanacaste, costa rica. J Clin Microbiol. 2007;45(5):144754. doi:10.1128/JCM.02580-06.

11. Sargent A, Bailey A, Almonte M, Turner A, Thomson C, Peto J, et al Prevalence of type-specific HPV infection by age and grade of cervical cytology: data from the ARTISTIC trial. Br J Cancer. 2008;98(10):1704-9. doi: 10.1038/sj.bjc.6604324.

12. Bonde J, Rebolj M, Ejegod D, Preisler S, Lynge E, Rygaard C. HPV prevalence and genotype distribution in a population-based split-sample study of wellscreened women using CLART HPV2 human papillomavirus genotype microarray system. BMC Infect Dis. 2014;14(1):413.

13. Goldman B, Rebolj M, Rygaard C, Preisler S, Ejegod DM, Lynge E, et al. Patterns of cervical coinfection with multiple human papilloma virus types in a screening population in denmark. Vaccine. 2013;31(12):1604-9. doi:10.1016/j.vaccine.2012.12.084.

14. Preisler S, Rebolj M, Untermann A, Ejegod DM, Lynge E, Rygaard C, et al. Prevalence of human papillomavirus in 5,072 consecutive cervical SurePath samples evaluated with the roche cobas HPV real-time PCR assay. PLoS One. 2013;8(3), e59765. doi:10.1371/journal.pone.0059765.

15. Rebolj M, Lynge E, Ejegod D, Preisler S, Rygaard C, Bonde J. Comparison of three human papillomavirus DNA assays and one mRNA assay in women with abnormal cytology. Gynecologic Oncology. 2014;135(3):474-80. doi:http://dx.doi.org/10.1016/j.ygyno.2014.10.014.

16. Rebolj M, Preisler S, Ejegod DM, Bonde J, Rygaard C, Lynge E. Prevalence of Human Papillomavirus Infection in Unselected SurePath Samples Using the 
APTIMA HPV mRNA Assay. The Journal of Molecular Diagnostics. 2013;15(5): 670-7. doi:http://dx.doi.org/10.1016/j.jmoldx.2013.04.002.

17. Rebolj M, Preisler S, Ejegod DM, Rygaard C, Lynge E, Bonde J. Disagreement between human papillomavirus assays: an unexpected challenge for the choice of an assay in primary cervical screening. PLoS One. 2014;9(1), e86835. doi:10.1371/journal.pone.0086835.

18. Bjerregaard B, Larsen O. The danish pathology register. Scand J Public Health. 2011;39 Suppl 7:72-4.

19. Castle PE. Screening: HPV testing for cervical cancer: the good, the bad, and the ugly. Nat Rev Clin Oncol. 2010;7(7):364-5.

20. Roche. Cobas HPV test. https://www.hpv16and18.com/labs/medical-value/ assay-design.html. Accessed 12 August 2015

21. Hologic. APTIMA HPV Assay Package Insert. http://www.hologic.com/ package-inserts/clinical-diagnosticsand-blood-screening/assays-and-tests/ aptima-hpv-assay Accessed 11 July 2016.

22. Steinau M, Patel SS, Unger ER. Efficient DNA extraction for HPV genotyping in formalin-fixed, paraffin-embedded tissues. J Mol Diagn : JMD. 2011;13(4): 377-81. doi:10.1016/j.jmoldx.2011.03.007.

23. Meites E, Lin C, Unger ER, Steinau M, Patel S, Markowitz LE, et al. Can clinical tests help monitor human papillomavirus vaccine impact? Int J Cancer. 2013;133(5):1101-6. doi:10.1002/ijc.28115.

24. Chranioti A, Spathis A, Aga E, Meristoudis C, Pappas A, Panayiotides I, et al. Comparison of two commercially available methods for HPV genotyping: CLART HPV2 and linear array HPV genotyping tests. Anal Quant Cytol Histol. 2012;34:257-63.

25. Mejlhede N, Pedersen B, Frisch M, Fomsgaard A. Multiple human papilloma virus types in cervical infections: competition or synergy? APMIS. 2010;118: 346-52.

26. Pista A, Verdasca N, Oliveira A. Clinical performance of the CLART human papillomavirus 2 assay compared with the hybrid capture 2 test. J Med Virol. 2011;83:272-6.

27. Szarewski A, Ambroisine L, Cadman L, Austin J, Ho L, Terry G, et al. Comparison of predictors for high-grade cervical intraepithelial neoplasia in women with abnormal smears. Cancer Epidemiol Biomarkers Prev. 2008;17: 3033-42.

28. Ejegod DM, Rebolj M, Bonde J. Comparison of analytical and clinical performance of CLART HPV2 genotyping assay to linear array and hybrid capture 2: a split-sample study. BMC Cancer. 2015;15:216. doi:10.1186/ s12885-015-1223-z.

29. Eklund C, Forslund O, Wallin K-L, Dillner J. Global improvement in genotyping of human papillomavirus DNA: the 2011 HPV LabNet international proficiency study. J Clin Microbiol. 2014;52(2):449-59. doi:10.1128/jcm.02453-13.

30. Kovacic MB, Castle PE, Herrero R, Schiffman M, Sherman ME, Wacholder S, et al. Relationships of human papillomavirus type, qualitative viral load, and Age with cytologic abnormality. Cancer Res. 2006;66(20):10112-9. doi:10.1158/0008-5472.can-06-1812.

31. Lowe B, O'Neil D, Loeffert D, Nazarenko I. Distribution of Human papillomavirus load in clinical specimens. Journal of Virological Methods. 2011;173(1):150-2. doi:http://dx.doi.org/10.1016/j.jviromet.2011.01.018.

32. Siriaunkgul SUU, Suwiwat S, Settakorn J, Sukpan K, Srisomboon J, Khunamornpong S. Prognostic value of HPV18 DNA viral load in patients with early-stage neuroendocrine carcinoma of the uterine cervix. Asian Pac J Cancer Prev. 2012;13:3281-5.

33. Xi LF, Edelstein ZR, Meyers C, Ho J, Cherne SL, Schiffman M. Human papillomavirus types 16 and 18 DNA load in relation to coexistence of other types, particularly those in the same species. Cancer Epidemiol Biomarkers Prev. 2009;18(9):2507-12. doi:10.1158/1055-9965.epi-09-0482.

\section{Submit your next manuscript to BioMed Central and we will help you at every step:}

- We accept pre-submission inquiries

- Our selector tool helps you to find the most relevant journal

- We provide round the clock customer support

- Convenient online submission

- Thorough peer review

- Inclusion in PubMed and all major indexing services

- Maximum visibility for your research

Submit your manuscript at www.biomedcentral.com/submit
Biomed Central 